\title{
Resistance of Diploid Vaccinium spp. to the Fruit Rot Stage of Mummy Berry Disease
}

\author{
A. W. Stretch, M. K. Ehlenfeldt, and V. Brewster, USDA-ARS; and N. Vorsa and J. Polashock, Department of \\ Horticulture, Rutgers University, Philip E. Marucci Center for Blueberry and Cranberry Research and Extension, \\ Chatsworth, NJ 08019
}

\begin{abstract}
Stretch, A. W., Ehlenfeldt, M. K., Brewster, V., Vorsa, N., and Polashock, J. 2001. Resistance of diploid Vaccinium spp. to the fruit rot stage of mummy berry disease. Plant Dis. 85:27-30.

Mummy berry disease caused by Monilinia vaccinii-corymbosi is the most widespread economically important problem of cultivated blueberry in North America. In an attempt to identify new sources of resistance to the fruit rot (mummification) phase of mummy berry, 140 accessions from a total of 21 populations from seven wild diploid species of blueberry were evaluated for resistance under greenhouse conditions. Six isolates of $M$. vaccinii-corymbosi from three states were used as inoculum. A highly resistant response to mummy berry fruit rot was exhibited by all accessions of Vaccinium boreale, V. myrtilloides, V. pallidum, and V. tenellum, and by most accessions of $V$. darrowi. Most of the $V$. corymbosum and $V$. elliottii accessions were moderately to highly susceptible. Introgression of the resistance found in the wild diploid species into horticulturally desirable cultivars could significantly improve available resistance.
\end{abstract}

Additional keyword: screening

Mummy berry disease of cultivated highbush blueberry (Vaccinium corymbosum L.) occurs in most growing areas in North America and in certain situations causes serious economic loss (6). The fungal causal agent, Monilinia vaccinii-corymbosi (Reade) Honey, overwinters as pseudosclerotia in mummified fruit on the soil surface, and apothecia develop in early spring from the pseudosclerotia (1). Primary infection occurs when ascospores, forcibly ejected from apothecia, infect noncuticularized leaf, stem, and flower-bud tissues, causing a blight of new growth. In the secondary infection phase, conidia produced on the surface of blighted tissues are carried by wind and pollinating insects to flower stigmas, where they germinate and grow down the style into the ovary. Hyphae colonize and fill the fruit locules, but no visible exterior symptoms appear until near harvest, when infected berries turn a salmon or cream color and begin to dry up (mummify) and drop to the ground.

Resistance of certain highbush blueberry cultivars to the primary, secondary, or both infective phases of the fungus has been documented for many years $(13,14,17)$.

Corresponding author: M. K. Ehlenfeldt

E-mail: mehlenfeldt@ars.usda.gov

Accepted for publication 8 September 2000

Publication no. D-2000-1023-02R

This article is in the public domain and not copyrightable. It may be freely reprinted with customary crediting of the source. The American Phytopathological Society, 2001.
Recently, over 50 cultivars were evaluated for resistance to the shoot blighting phase of the disease under controlled conditions (16). Resistance was determined to be a combination of biochemical and avoidance mechanisms. Avoidance occurred through late vegetative shoot emergence; hence, susceptible host tissue was not present when fungal inoculum was available. A small number of cultivars exhibited a significant level of biochemical resistance $(8,11)$. A few cultivars with a significant level of biochemical resistance to the fruit rot phase of infection were also found in an evaluation of 70 cultivars (15).

Wild blueberry species have been exploited for favorable alleles for genetic improvement of commercial cultivars (9). The diploid species $V$. myrtilloides Michx. has been suggested as a potential source of mummy berry resistance (9); however, Batra (2) demonstrated susceptibility to the shoot blight phase. Batra did not observe mummified fruit on the diploid species $V$. pallidum Ait. and $V$. darrowi Camp in his extensive research on M. vaccinii-corymbosi and its host relationships (2). The availability of the aforementioned species, as well as other diploid blueberry species, $V$. boreale Hall \& Aalders, V. corymbosum L., V. elliottii Chapm., and V. tenellum Ait. (4) provided an opportunity to evaluate geographically diverse populations of these Vaccinium spp. for resistance to the fruit rot phase of mummy berry disease.

\section{MATERIALS AND METHODS}

Seven diploid blueberry species were evaluated for resistance to the fruit-rotting phase of the mummy berry fungus. The collection of these species were described by Bruderle and Vorsa (4). The species, population, number of plants inoculated within a population, and locality of origin of the populations are shown in Table 1 . Plants used in these trials were grown in 3liter plastic pots and overwintered in a greenhouse maintained at a minimum of 2 to $3^{\circ} \mathrm{C}$ to prevent winter injury to the southern species. The winter conditions provided sufficient chilling to allow normal flower development when the plants were moved to a heated greenhouse in early March to conduct the tests.

Isolates of $M$. vaccinii-corymbosi used in these tests were obtained from a culture collection maintained in the laboratory of P. V. Oudemans at the Rutgers Philip E. Marucci Center for Blueberry and Cranberry Research and Extension, Chatsworth, NJ. The geographical sources and year of isolation of conidial isolates of $M$. vaccinii-corymbosi used in these tests are listed in Table 2. Fungal cultures were isolated by surface sterilizing pseudosclerotia for $5 \mathrm{~min}$ in a $95 \%$ ethanol:5\% sodium hypochlorite solution $(1: 1 \mathrm{vol} / \mathrm{vol})$ and placing pseudosclerotia onto fullstrength potato dextrose agar (PDA; Becton Dickinson Microbiological Systems, Cockeysville, MD). Cultures were maintained on PDA slants in $3^{\circ} \mathrm{C}$ refrigerated conditions and subcultured twice a year. To induce production of conidia, an agar plug from an actively growing culture was transferred to the surface of a cellulose membrane (Gelman Sciences, Ann Arbor, MI) placed on the surface of V8 agar in 100-mm petri dishes (3). Cultures were selected on the basis of prolific sporulation and diversity of geographic origin. Conidia produced on 1- to 2-week-old cultures incubated at room temperature (21 to $23^{\circ} \mathrm{C}$ ) on the laboratory bench were used as inoculum. After hand pollinating the blueberry flowers, M. vaccinii-corymbosi conidia were transferred from the cellulose membranes to the flower stigma with a camelhair brush. No attempt was made to quantify the number of conidia applied to each stigma. Pollen was bulked from several plants of the same species being pollinated or inoculated. When pollen from the species plants was not available, pollen from diploid $(2 \times) V$. corymbosum was used. Most of the plant accessions used in 1995 were used again in 1996. 
In 1995, three isolates of M. vaccinii-corymbosi were used to inoculate each test plant (Table 2). A total of 20 flowers (four arbitrarily chosen clusters containing five receptive flowers) were inoculated with each of the three isolates for a total of 60 flowers. Receptivity was assessed by examining stigmas for exudate production. Unused or unsuitable flowers in any selected cluster were removed. Each cluster of five flowers was tagged with a colored tag, a different color for each isolate. This process was repeated in 1996 with three new isolates (Table 2). The pathogenicity of each isolate was checked by inoculating known susceptible plants; diploid $V$. corymbosum plants were used in 1995 and the tetraploid $(4 \times)$ cv. Murphy in 1996.

Fruit was picked just prior to blue color development to avoid potential loss from abscission of mature fruit. Each fruit was sliced in half and observed for the distinctive white masses of mycelium of the mummy berry fungus within the fruit. Data were expressed as percentage of $M$. vaccinii-corymbosi-infected fruit out of the total number picked for each genotype.
Reference numbers of genotypes used per population are shown in Table 1. For population evaluations, the number of genotypes used ranged from three to seven in 1995 and from two to eight in 1996, with five to six being average. Across species, the number of genotypes per species used ranged from 9 to 30 in 1995 and from 12 to 25 in 1996.

Because three of seven species in 1995 and four of seven species in 1996 had only zero values and heterogeneity of variance was large, a $\chi^{2}$ analysis was used to test the null hypothesis that species or group responses differed from the overall experimental group response. Contingency $\chi^{2} s$ were calculated for comparisons among species, between types (highbush versus lowbush), within types, and within species. Years were analyzed separately because control cultivars and some populations differed between 1995 and 1996. Inoculum isolates were analyzed for differential virulence on species groups with non-zero infection rates using the general linear model (GLM) of SAS (SAS Institute, Cary, NC).

Table 1. Taxon, population, number of plants inoculated with Monilinia vaccinii-corymbosi $(\mathrm{N})$, percent fruit rot, and collection locality of diploid blueberry (Vaccinium spp.) populations

\begin{tabular}{|c|c|c|c|c|c|c|}
\hline \multirow[b]{2}{*}{ Taxon } & \multirow[b]{2}{*}{ Population } & \multicolumn{2}{|c|}{$\mathbf{N}$} & \multicolumn{2}{|c|}{$\operatorname{Rot}(\%)^{\mathbf{a}}$} & \multirow[b]{2}{*}{ Locality } \\
\hline & & 1995 & 1996 & 1995 & 1996 & \\
\hline$V$. boreale & NJ88-29 & 6 & 6 & 0.0 & 0.0 & Cape Breton Co., NS, Canada \\
\hline V. boreale & NJ88-30 & 6 & 6 & 0.0 & 0.0 & Cape Breton Co., NS, Canada \\
\hline V. corymbosum & NC79-76b & 6 & 7 & 11.0 & 11.1 & Montgomery Co., NC, USA \\
\hline V. corymbosum & NC84-6b & 6 & 6 & 14.6 & 11.0 & Lake Co., FL, USA \\
\hline V. darrowi & NC84-6a & 6 & 6 & 0.0 & 0.5 & Lake Co., FL, USA \\
\hline V. darrowi & NJ88-06 & 6 & 8 & 0.0 & 0.0 & Santa Rosa Co., FL, USA \\
\hline V. darrowi & NJ88-06-2 & 6 & & 0.0 & & Santa Rosa Co., FL, USA \\
\hline V. darrowi & NJ88-12 & 5 & 7 & 0.0 & 0.0 & Liberty Co., FL, USA \\
\hline V. darrowi & NJ88-13 & 7 & 4 & 3.1 & 0.0 & Liberty Co., FL, USA \\
\hline V. elliottii & NJ88-01 & 5 & 5 & 22.4 & 12.5 & Bibb Co., GA, USA \\
\hline V. elliottii & NJ88-04 & 6 & 6 & 19.4 & 20.2 & Santa Rosa Co., FL, USA \\
\hline V. elliottii & NJ88-16 & 6 & 6 & 9.4 & 37.4 & Stone Co., MS, USA \\
\hline V. myrtilloides & NJ88-26 & 4 & 4 & 0.0 & 0.0 & Chippewa Co., MI, USA \\
\hline V. myrtilloides & NJ88-27 & 5 & 5 & 0.0 & 0.0 & Bayfield Co., WI, USA \\
\hline V. myrtilloides & NJ88-28 & $\ldots$ & 4 & $\ldots$ & 0.0 & Alger Co., MI, USA \\
\hline$V$. pallidum & NJ88-18 & 6 & 2 & 0.0 & 0.0 & Burlington Co., NJ, USA \\
\hline V. pallidum & NJ91-2 & 3 & 5 & 0.0 & 0.0 & Barnstable Co., MA, USA \\
\hline V. pallidum & NC79-76a & 5 & 5 & 0.0 & 0.0 & Montgomery Co., NC, USA \\
\hline V. pallidum & NC79-76-90 & 4 & & 0.0 & & Montgomery Co., NC, USA \\
\hline V. tenellum & NC83-9 & 5 & 5 & 0.0 & 0.0 & Bladen Co., NC, USA \\
\hline V. tenellum & NC87-9 & 6 & 4 & 0.0 & 0.0 & Brunswick Co., NC, USA \\
\hline V. tenellum & NC87-9(90) & $\ldots$ & 3 & $\ldots$ & 0.0 & Brunswick Co., NC, USA \\
\hline V. tenellum & NC88-31 & 6 & 5 & 0.0 & 0.0 & Turner Co., GA, USA \\
\hline
\end{tabular}

${ }^{a}$ Each percentage value is the sum of mummy berry fruit rot per plant divided by the number of plants used per population. Each plant percentage was based on number of fruit infected divided by the total number of fruit set out of 60 flowers. Number of plants utilized ranged from three to seven in 1995 and two to seven in $1996 ; \ldots=$ not tested.

Table 2. Sources of Monilinia vaccinii-corymbosi isolates used in 1995 and 1996 tests

\begin{tabular}{lcll}
\hline Year & Isolate code $^{\mathbf{a}}$ & Cultivar & \multicolumn{1}{c}{ Location } \\
\hline 1995 & $936-10-12$ & Jersey & Burlington Co., NJ \\
1995 & $9424-X-89$ & Croatan & Duplin Co., NC \\
1995 & $9412-X-1$ & Bluecrop & Burlington Co., NJ \\
1996 & $9422-X-16$ & Croatan & Duplin Co., NC \\
1996 & $9514-X-7$ & Bluecrop & Ottawa Co., MI \\
1996 & $944-37-4$ & Weymouth & Burlington Co., NJ \\
\hline
\end{tabular}

${ }^{a}$ The first two digits of code number indicate year culture was isolated.

\section{RESULTS}

Percent fruit set was examined to evaluate whether some species gave the appearance of low relative infection levels in developed fruit because of high levels of flower abortion levels after infection (Table 3). Although average fruit set varied across species (i.e., V. myrtilloides at $15 \%$ in 1995 and $V$. corymbosum at $37 \%$ in 1996), most fruit set percentages fell in the range of 40 to $70 \%$. In both of the cited cases of lower fruit set, reasonable fruit set occurred in the other year, and infection levels were similar in both years. The overall contingency $\chi^{2}$ indicated that there were significant differences among species in their response to $M$. vaccinii-corymbosi in both 1995 and $1996\left(\chi^{2}{ }_{1995}=110.4, P \leq\right.$ 0.001, $\left.\chi^{2}{ }_{1996}=70.3, P \leq 0.001\right)$. In both 1995 and 1996, the lowbush species $V$. boreale, $V$. myrtilloides, V. pallidum, and $V$. tenellum had no mummified fruit (Table 3). Another lowbush species, V. darrowi, had only 1 plant (of 30) in both 1995 and 1996 that developed mummified fruit. In 1995, this infection occurred on a single clone in population NJ88-13, using isolate $9412-\mathrm{X}$ 1 and, in 1996, on a single clone in population NC84-6a using isolate 944-37-4 (Table 1). Highly significant $\chi^{2}$ s (Table 3 ) were obtained contrasting lowbush versus highbush infection rates, whereas differences among species within the type (highbush or lowbush) were not significant except for the highbush species group in 1995. This group was significant at the margin of the category $(P=0.05)$, and was different from the other populations within the group by having greater numbers of plants with high percentages of infection. The $\chi^{2}$ analysis of variation among populations within a species was not significant (data not shown).

The group of five $V$. corymbosum $(2 \times)$ plants used as susceptible controls for infectivity of the inoculum developed considerably more mummy berry rot $(47.7 \%)$ than all of the test species in 1995. The highbush cv. Murphy $(4 \times)$ that was used as the susceptible control in 1996 was comparable to the $2 \times V$. corymbosum test populations (11.0\%; Table 3). In previous evaluations, however, Murphy exhibited a susceptible reaction that averaged approximately $35 \%$ fruit infection across a 3 year period (15). This apparently low infection frequency on Murphy in 1996 suggests some variability with the control inoculations, but infection rates on the diploid species remained fairly consistent across the 2 years.

Six different single conidial isolates of M. vaccinii-corymbosi were used in the 2 years of this study (Tables 2 and 4). In both 1995 and 1996, no difference in relative virulence was evident among isolates when isolates were compared across the susceptible species $V$. corymbosum and $V$. elliottii $\left(F_{1995}=1.04, P=0.35, F_{1996}=2.33, P=\right.$ $0.11)$. Minor variations occurred with re- 
spect to relative virulence of individual isolates on $V$. corymbosum versus $V$. elliottii. The general consistency of the response of species to the isolates suggests that the isolates represented a suitable collection for a broad-based screening for resistance.

\section{DISCUSSION}

The results of this investigation show that a very high level of resistance to mummy berry fruit infection exists in representative plants in four out of seven diploid blueberry species evaluated. The lowbush diploid blueberry species, $V$. boreale, $V$. darrowi, V. myrtilloides, V. pallidum, and $V$. tenellum, demonstrated high levels of mummy berry fruit rot resistance, whereas the highbush diploid species, $V$. corymbosum and V. elliottii, exhibited only moderate or poor resistance. Our sources of inoculum all originated from cultivated V. corymbosum cultivars, and it is an important consideration that the highbush isolates may be less virulent or nonvirulent on lowbush species. Our finding that $V$. myrtilloides is highly resistant was not consistent with the observation of Batra (1), who observed a population of seedlings of $V$. myrtilloides that developed mummy berry fruit rot under field conditions. Also in contrast to our results, Batra (2) observed mummified fruit caused by $M$. vaccinii-corymbosi on $V$. tenellum in Georgia. Our results confirmed the susceptibility to mummy berry fruit rot of $V$. corymbosum and V. elliottii and the high levels of resistance of $V$. pallidum observed by Batra $(1,2)$ in field and greenhouse studies. The sources of Batra's $M$. vacciniicorymbosi inoculum isolates were not explicitly described, but it seems likely that most originated on $V$. corymbosum material, and hence were very similar to our inoculum. The differences in resistance noted for the lowbush blueberry diploid species $V$. darrowi, V. myrtilloides, and $V$. tenellum between our studies and those of Batra $(1,2)$, who found them resistant, susceptible, and susceptible, respectively, probably reflect variability in plant genotype within these species. These results suggest that specific populations of $V$. myrtilloides and $V$. tenellum may represent a previously unrecognized source of resistance to mummy berry fruit rot. The highly resistant reaction of representative plants of $V$. boreale to the fruit rot phase of $M$. vaccinii-corymbosi also has not previously been reported.

$V$. darrowi, which, as a species, exhibited significant levels of resistance in this study, has been used extensively in southern highbush blueberry breeding. In a 1996 evaluation of highbush blueberry cultivars for resistance to mummy berry fruit rot (15), the cultivars Blue Ridge, Cape Fear, Cooper, Legacy, Sharpblue, and Sierra exhibited fruit infection levels of 27, $0,20,4,8$, and $20 \%$, respectively. These cultivars all have a 20 to $25 \%$ genetic contribution from $V$. darrowi, primarily from the selection Florida-4B (FL-4B) (7). It should be noted that the selection FL-4B has not, to this point, been screened specifically for fruit infection resistance. These data do not support any concerted inheritance of mummy berry fruit rot resistance through FL-4B. However, it should also be noted that none of these cultivars were selected specifically for mummy berry resistance. Thus, with one or more backcross generations to highbush after initial incorporation, any resistance genes may have been diluted or eliminated, particularly if they were linked to undesirable traits.

The rather narrow genetic base for the principal northern highbush cvs. Bluecrop, Blueray, Croatan, Duke, Elliott, Jersey, and Weymouth (12) is built principally from the wild tetraploid selections Brooks, Sooy, and Rubel (10). Resistance genes from diploid species would be a valuable addition to the resistance to both phases of this disease once the nature and inheritance of resistance is determined. Utilization of $2 n$ gametes in breeding should permit primary incorporation of this germplasm and allow for further evaluation of its behavior and interactions with cultivated germplasm (5). Evaluation of resistance to the shoot blighting phase of $M$. vaccinii-corymbosi in diploid blueberry species should offer

Table 4. Infection frequencies of isolates on diploid blueberry species having more than $1 \%$ infection in 1995 and 1996

\begin{tabular}{|c|c|c|c|c|c|c|}
\hline \multirow[b]{3}{*}{ Vaccinium spp. } & \multicolumn{6}{|c|}{ Infection on populations (\%) } \\
\hline & \multicolumn{3}{|c|}{1995} & \multicolumn{3}{|c|}{1996} \\
\hline & 936-10-12 & 9424-X-89 & 9412-X-1 & 9422-X-16 & 9514-X-7 & $944-37-4$ \\
\hline V. corymbosum $(2 x)$ & 7.2 & 21.6 & 12.9 & 15.2 & 6.4 & 17.7 \\
\hline V. elliottii & 14.5 & 17.8 & 17.0 & 34.4 & 10.1 & 15.3 \\
\hline Average $^{a}$ & 11.8 & 19.2 & 15.6 & 26.7 & 8.4 & 16.5 \\
\hline
\end{tabular}

a Average across V. corymbosum and V. elliottii. Significant differences were not observed between isolates in either 1995 or 1996.

Table 3. Fruit set, percent fruit rot, fruit rot distribution ranges, and contingency $\chi^{2}$ values for diploid Vaccinium spp. populations and $V$. corymbosum controls inoculated with Monilinia vaccinii-corymbosi in 1995 and 1996

\begin{tabular}{|c|c|c|c|c|c|c|c|c|c|c|c|c|}
\hline \multirow[b]{3}{*}{ Taxon, type ${ }^{\text {b }}$} & \multicolumn{6}{|c|}{$1995^{a}$} & \multicolumn{6}{|c|}{1996} \\
\hline & \multirow[b]{2}{*}{ Set $(\%)$} & \multirow[b]{2}{*}{$\operatorname{Rot}(\%)$} & \multicolumn{3}{|c|}{ Distribution (no.) } & \multirow[b]{2}{*}{$\chi^{2}$} & \multirow[b]{2}{*}{ Set $(\%)$} & \multirow[b]{2}{*}{$\operatorname{Rot}(\%)$} & \multicolumn{3}{|c|}{ Distribution (no.) } & \multirow[b]{2}{*}{$\chi^{2}$} \\
\hline & & & $\mathbf{0}$ & $1-20$ & $21-40$ & & & & $\mathbf{0}$ & $\mathbf{1 - 2 0}$ & $21-40$ & \\
\hline V. boreale, $\mathrm{L}$ & 63 & 0.0 & 12 & 0 & 0 & $\ldots$ & 55 & 0.0 & 12 & 0 & 0 & $\ldots$ \\
\hline V. myrtilloides, $\mathrm{L}$ & 15 & 0.0 & 9 & 0 & 0 & $\ldots$ & 57 & 0.0 & 12 & 0 & 0 & $\ldots$ \\
\hline V. pallidum, L & 55 & 0.0 & 29 & 1 & 0 & $\ldots$ & 61 & 0.0 & 10 & 0 & 0 & $\ldots$ \\
\hline V. tenellum, $\mathrm{L}$ & 43 & 0.0 & 17 & 0 & 0 & $\ldots$ & 70 & 0.0 & 17 & 0 & 0 & $\ldots$ \\
\hline V. darrowi, $\mathrm{L}$ & 58 & 0.8 & 29 & 1 & 0 & $\ldots$ & 61 & 0.1 & 22 & 1 & 0 & $\ldots$ \\
\hline V. corymbosum, $\mathrm{H}$ & 60 & 11.9 & 4 & 4 & 4 & $\ldots$ & 37 & 11.0 & 5 & 4 & 2 & $\ldots$ \\
\hline V. elliottii, H & 61 & 16.3 & 3 & 10 & 4 & $\ldots$ & 44 & 24.8 & 3 & 6 & 7 & $\ldots$ \\
\hline V. corymbosum-controls, $\mathrm{H}^{\mathrm{c}}$ & 43 & 47.7 & 3 & 2 & $10^{\mathrm{c}}$ & $\ldots$ & 80 & 10.0 & 11 & 10 & $3^{c}$ & $\ldots$ \\
\hline \multicolumn{13}{|l|}{ Contingency $\chi^{2}$ values $^{\mathrm{d}}$} \\
\hline Among species & $\ldots$ & $\ldots$ & $\ldots$ & $\ldots$ & $\ldots$ & $110.4^{* * * *}$ & $\ldots$ & $\ldots$ & $\ldots$ & $\ldots$ & $\ldots$ & $70.3^{* * * *}$ \\
\hline Lowbush vs. highbush & $\ldots$ & $\ldots$ & $\ldots$ & $\ldots$ & $\ldots$ & $91.3^{* * *}$ & $\ldots$ & $\ldots$ & $\ldots$ & $\ldots$ & $\ldots$ & $56.1^{* * * *}$ \\
\hline Within lowbush & $\ldots$ & $\ldots$ & $\ldots$ & $\ldots$ & $\ldots$ & $1.3^{\mathrm{NS}}$ & $\ldots$ & $\ldots$ & $\ldots$ & $\ldots$ & $\ldots$ & $2.3^{\mathrm{NS}}$ \\
\hline Within highbush & $\ldots$ & $\ldots$ & $\ldots$ & $\ldots$ & $\ldots$ & $9.3^{*}$ & $\ldots$ & $\ldots$ & $\ldots$ & $\ldots$ & $\ldots$ & $6.4^{\mathrm{NS}}$ \\
\hline
\end{tabular}


additional options for resistance breeding to both phases of mummy berry disease.

\section{ACKNOWLEDGMENTS}

We thank K. Adams, C. Constantelos, K. Gaun, and R. Hagan for technical support; J. Lehman and P. Oudemans for advice and counsel during the course of the study; and T. A. Chen and P. Oudemans for critical reading of the manuscript.

\section{LITERATURE CITED}

1. Batra, L. R. 1983. Monilinia vaccinii-corymbosi (Sclerotiniaceae): its biology on blueberry and comparison with related species. Mycologia 75:131-152.

2. Batra, L. R. 1991. World Species of Monilinia (Fungi): Their Ecology, Biosystematics and Control. J. Cramer, Berlin.

3. Brewster, V., Stretch, A. W., and Ehlenfeldt, M. K. 1995. A technique for producing conidia of Monilinia vaccinii-corymbosi on artificial media. (Abstr.) Phytopathology 85:1200.

4. Bruederle, L. P., and Vorsa, N. 1994. Genetic differentiation of diploid blueberry, Vaccinium sect. Cyanococcus (Ericaceae). Syst. Bot. 19:337-349.

5. Draper, A. D., Galletta, G. J., and Ballington, J. R. 1982. Breeding methods for improving southern tetraploid blueberries. J. Am. Soc. Hortic. Sci. 107:106-109.

6. Eck, P., 1988. Blueberry Science. Rutgers Univ. Press, New Brunswick, NJ.

7. Ehlenfeldt, M. K. 1994. The genetic composition and tetrasomic inbreeding coefficients of highbush blueberry cultivars. HortScience 29:1342-1345

8. Ehlenfeldt, M. K., Stretch, A. W., and Brewster, V. 1996. Genetic and morphological factors affecting mummy berry blight resistance in highbush blueberry cultivars. HortScience 31:252-254.

9. Galletta, G. J. 1975. Blueberries and cranberries. Pages 154-196 in: Advances in Fruit Breeding. J. Janick and J. N. Moore, eds. Purdue University Press, West Lafayette, IN.

10. Hancock, J. F., and Siefker, J. H. 1982. Levels of inbreeding in highbush blueberry cultivars. HortScience 17:363-366.

11. Lehman, J. S., and Oudemans, P. V. 1997. Phenology of apothecium production in populations of Monilinia vaccinii-corymbosi from early- and late-maturing blueberry cultivars. Phytopathology 87:218-223.

12. Moore, J. N. 1993. Blueberry cultivars of North America. HortTechnology 3:370-374.

13. Nelson, J., and Bittenbender, H. C. 1971. Mummy berry disease occurrence in a blueberry selection test planting. Plant Dis. Rep. 55:651-653.

14. Pepin, H. S., and Toms, H. N. W. 1969. Susceptibility of highbush blueberry varieties to Monilinia vaccinii-corymbosi. Phytopathology 59:1876-1878.

15. Stretch, A. W., and Ehlenfeldt, M. K. Resistance to the fruit infection phase of mummy berry disease in highbush blueberry cultivars. HortScience. In press.

16. Stretch, A. W., Ehlenfeldt M. K., and Brewster V. 1995. Mummy berry blight resistance in highbush blueberry cultivars. HortScience 30:589-591.

17. Varney, E. H., and Stretch A. W. 1966. Diseases and their control. Pages 236-279 in: Blueberry Culture. P. Eck and N. F. Childers, eds. Rutgers Univ. Press, New Brunswick, NJ. 